\title{
Biomechanical Considerations in the Unruptured Cerebral Aneurysm Study (UCAS Japan): Rupture Risk and True Stress of Wall
}

\author{
Fumio Nogata ${ }^{*}$, Yasunari Yokota², Yoko Kawamura3 ${ }^{3}$, Hiroyuki Morita4, Yoshiyuki Uno5, \\ Tetsuya Mouri ${ }^{6}$, William R. Walsh ${ }^{7}$, Takakahiko Kawamura ${ }^{8}$, Nigishi Hotta ${ }^{9}$, Kenji Kagechika10
}

${ }^{1}$ Gifu University, Gifu, Japan

${ }^{2}$ Department of Electrical, Electronic and Computer Engineering, Faculty of Engineering, Gifu University, Gifu, Japan

${ }^{3}$ Faculty of Engineering, Gifu University, Gifu, Japan

${ }^{4}$ Department of General Medicine and General Internal Medicine, Gifu University Graduate School of Medicine, Gifu, Japan

${ }^{5}$ Department of General Medicine, Gifu Prefectural General Medical Center, Gifu, Japan

${ }^{6}$ Department of Mechanical Engineering, Faculty of Engineering, Gifu University, Gifu, Japan

${ }^{7}$ Prince of Wales Hospital, University of New South Wales, Kensington, Australia

${ }^{8}$ Chubu Rosai Hospital, Aichi, Japan Diabetes and Endocrine Internal Medicine, Nagoya, Japan

${ }^{9}$ Nagoya University and Chubu Rosai Hospital, Internal Medicine, Nagoya, Japan

${ }^{10}$ Toyama Prefectural Rehabilitation Hospital and Support Center for Children with Disabilities, Toyama, Japan

Email: *nognog2525@yahoo.co.jp,nogata@gifu-u.ac.jp

How to cite this paper: Nogata, F., Yokota, Y., Kawamura, Y., Morita, H., Uno, Y., Mouri, T., Walsh, W.R., Kawamura, T., Hotta, N. and Kagechika, K. (2021) Biomechanical Considerations in the Unruptured Cerebral Aneurysm Study (UCAS Japan): Rupture Risk and True Stress of Wall. Journal of Biosciences and Medicines, 9, 172-189. https://doi.org/10.4236/jbm.2021.910015

Received: September 3, 2021

Accepted: October 24, 2021

Published: October 27, 2021

Copyright (c) 2021 by author(s) and Scientific Research Publishing Inc. This work is licensed under the Creative Commons Attribution International License (CC BY 4.0).

http://creativecommons.org/licenses/by/4.0/ (c) (i) Open Access

\begin{abstract}
When an unruptured aneurysm is found, deciding whether to operate or follow up is one of the most important issues. There are guidelines for making the best final decision on treatment, taking into account the effectiveness of diagnostic and therapeutic devices and the risk-benefit ratio of patients, caregivers, and healthcare professionals. The guidelines evidence-based of large clinical data for this purpose are presented by national medical societies. As one of the rupture risk indicators, there is the hazard risk ratio derived by the UCAS Japan research group based on the statistical method of 6697 aneurysms in 5720 patients with cerebral aneurysms of $3 \mathrm{~mm}$ or more. Therefore, we investigated the biomechanical significance of this hazard risk ratio using a spherical aneurysm model. It was revealed that 1) the reason why the frequency of aneurysm rupture is relatively high up to about $10 \mathrm{~mm}, 2$ ) the UCAS hazard risk ratio corresponds to stress of the aneurysm wall, and the true stress can be calculated by multiplying the patient's blood pressure, and 3 ) the factors that cause the daughter's sac (irregular protrusion of the aneurysm wall). In addition, our two methods for measuring the strength of the
\end{abstract}


blood vessel wall of an individual patient were described.

\section{Keywords}

Cerebral Aneurysm, Rupture Risk, UCAS, Hazard Ratio, Biomechanics

\section{Introduction}

An aneurysm occurs in locally weakened part of the blood vessel wall, and the part that expands to more than 1.5 times the size of normal arterial diameter is called aneurysms [1] [2] [3]. And aneurysms can occur in any part of the body, but are most common in the brain, thoracic aneurysms, abdominal aortic aneurysms and legs [4] [5]. According to recent reports, diagnostic imaging using high-resolution magnetic resonance imaging (MRI) scans often accidentally finds a few millimeters of unruptured aneurysms. And it has become commonly known that a few percent of adults have an aneurysm, an average frequency of about 3 - 5 percent, mean age 50 years [6] [7] [8] [9]. The risk assessment of rupture, that is, evidence-based examination decisions for unruptured aneurysm, and whether surgery is necessary will take into account age related, smoking, hypertension, size, location, growth rate 5 years after diagnosis, family history of the aneurysm and so on [10]-[16].

In recent years, several guidelines including the latest issues have been published that provide comprehensive evidence-based recommendations for managing patients with unruptured aneurysms by the American Heart Association/Stroke Association [6], the European Society of Cardiology (ESC) [17] [18], and the Unruptured Cerebaral Aneurysm Study (UCAS) in Japan [19] [20] [21]. These guidelines aim to provide guidance for making the best final decision taking into consideration the effects of specific diagnostic or therapeutic measures and the risk-benefit ratio by patients, caregivers and responsible healthcare workers.

On the other hand, biomechanical considerations [22]-[30] are one of tools to understand the actual rupture risk assessment and to predict its occurrence. In particular, the aneurysm shape model obtained from the XCT and MRI images were analyzed by finite element analysis. And then the wall stress criterion [24] [26], rupture potential index (RPI) [27] [28], and the Peak Wall Rupture Risk Index (PWRI) [29] [30] based on mechanical and mathematical consideration [31] [32] have been proposed. However, in these reports, arterial wall stress is mainly discussed using nominal stress. The vessel wall is a soft material that deforms significantly when it ruptures. Therefore, it should use the true stress by the cross-sectional area at the time of rupture. Yangkun et al. reported [33] that the importance of the relationship between the wall and rupture risk based on the data measured skillfully the sphere model size of saccular aneurysm in real-time using a dielectric elastomer capacitance sensor. The authors also re- 
ported on the relativity of shape, size and wall strength for the rupture risk assessment of aneurysm [34]. And the three important physical quantities were shown to be the shape of the aneurysm, the true stress due to blood pressure, and the strength of the patient's artery wall.

In this paper, we demonstrated that the hazard risk value derived based on the clinical data statistics published by the UCAS Japan investigators corresponds to the stress of a spherical aneurysm model's wall. In addition, true stress of the vessel wall can calculate by multiplying the blood pressure. Therefore, the risk of rupture can be quantitatively examined by comparing it with the rupture strength in vivo of the patient's vessel wall. We also discussed the factors that cause the daughter sac (irregular protrusion of the aneurysm wall) from a mechanical point of view. It was also described how to measure the mechanical strength of a patient's vessel wall by using the echo image of the arterial wall and by using the natural frequency of the blood vessel wall due to the pulse wave.

\section{Materials and Methods}

\section{Data Source}

The UCAS Investigators examined about the natural course of unruptured cerebral aneurysms in a Japanese Cohort from 2001 for 8 years, follow-up period [19]. And out of 6697 studied (5720 patients) aneurysms of $3 \mathrm{~mm}$ or larger, average aneurysm size $5.7 \pm 3.6 \mathrm{~mm}$, mean age $62.5 \pm 10.3$ years, \% ruptured patients 0.93 year, and risk of rupture (the hazard ratio) by five size-category has shown as follows: 1) 3 to $4 \mathrm{~mm}$, 2) 5 to $6 \mathrm{~mm}, 3) 7$ to $9 \mathrm{~mm}, 4) 10$ to $24 \mathrm{~mm}$, and 5) $25 \mathrm{~mm}$ or larger.

Figure 1(a) shows the relation between aneurysm size and the hazard risk that

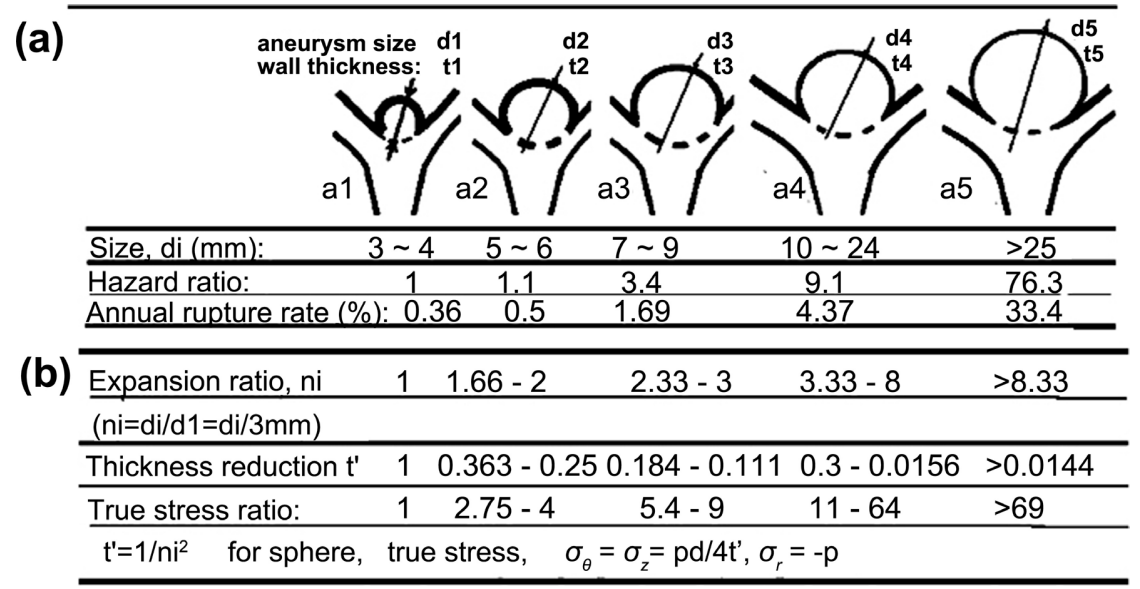

Figure 1. (a). Baseline characteristics of size and rupture risk, the classification derived by the Unruptured Cerebral Aneurysm Study (UCAS) based on 5720 patients (6697 aneurysms) over the age of 20 . The hazard ratio is the ratio with an aneurysm with a diameter of $3 \mathrm{~mm}$ as the denominator. The figure was quoted from the report [20] and partially revised. (b) Changes in true stress of the wall with the expansion of an aneurysm under internal pressure. Note that as the sphere expands, the wall thickness $\left(t^{\prime}\right)$ decreases by $1 /\left(n_{i}\right)^{2}$, creating very high stresses. 
have derived by the UCAS study [20] [21]: the aneurysm illustration was partially modified from the reference [20].

The hazard ratio has been quantified by the frequency of rupture, which means the rupture rate when the size category: $3-4 \mathrm{~mm}$ is set to one, from which the ratio abruptly increases. Annual rupture rate is the percentage of patients who ruptured in each size category. In this report below, the graphs were made with the data for the value of a $3 \mathrm{~mm}$ aneurysm as a ratio of one.

Figure $1(\mathrm{~b})$ shows the expansion ratio $\left(n_{i}\right)$, thickness reduction, and true stress ratio of sphere model under internal pressure. Note that the wall thickness $\left(t^{\prime}\right)$ of the expanded model is reduced by $1 /\left(n_{i}\right)^{2}$, resulting in very high stress.

\section{Results}

Figure 2 shows the relationship between aneurysm size and wall thickness reduction ratio calculated from the data of Figure 1(a). Here, the shape of the aneurysm was approximated by a sphere and a spheroid.

From the graph, it can be seen that the decrease in wall thickness is inversely proportional $\left(1 / n_{i}^{2}\right)$ to the square of the $n_{i}\left(=d_{l} / d_{1}\right)$ for sphere and about $\left(1.06 / n_{i}^{2}\right)$ for spheroid (in case of $a=1,2,3,4,5,6, b / a=0.4,0.5,0.6,0.8$, and $c / a=0.2,0.5$ [34]). Where $a, b, c$ are the length of three-axis of a spheroid. It should be noted that the thickness decrease rapidly between the size of $d_{i}=3-8 \mathrm{~mm}$. These results indicate the presence of large stresses on the vessel wall. Thus, it is essential to examine the problem of rupture with the true stress using the actual thickness. In Figure $1(\mathrm{~b})$, the expansion ratio $\left(n_{i}\right)$ and thickness reduction $(t)$ are shown.

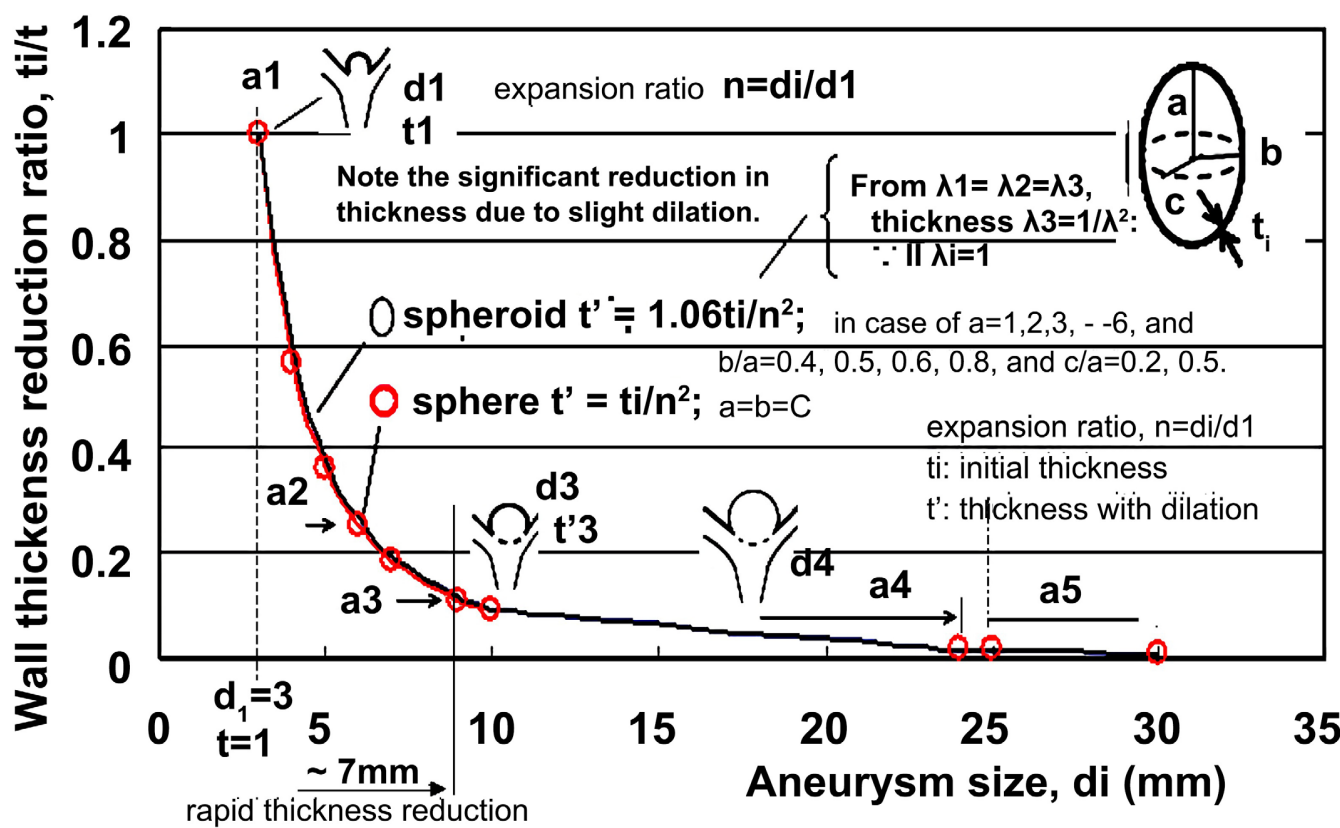

Figure 2. Wall thickness reduction ratios due to expansion of sphere and spheroid models. The thickness decreases in inverse proportion to the square of the size ratio $\left(n=d_{i} / d_{1}\right)$. From 1 to $10 \mathrm{~mm}(n=$ $10 / 3=3.3$ times), the wall thickness is significantly reduced (stress is increased). A $3 \mathrm{~mm}$ sphere $(a=$ $1.5 \mathrm{~mm}$ ) is under stressed of $0.75 p / t^{\prime}: p$ is blood pressure, $t^{\prime}$ is actual wall thickness. 
Next, we discuss the hazard risk value derived by UCAS researchers based on biomechanics.

\subsection{Biomechanical Considerations}

\section{True stress of arterial wall}

Figure 3 shows the stress expression for sphere and spheroid models. The wall of aneurysm is subjected to three stresses due to internal blood pressure: circumferential stress $\left(\sigma_{\theta}\right)$, longitudinal stress $\left(\sigma_{z}\right)$, and radial stress $\left(\sigma_{r}\right)$. In fact, these stresses need to be calculated by using true stress to solve the rupture problem, however other reports often discussed by using nominal stresses [24]-[32]. The true stress can be calculated from the specimen length at the fracture point and the constant volume (incompressible) condition: true stress $\sigma_{u}=\sigma_{o}\left(1+\varepsilon_{u}\right)=\sigma_{o} \lambda, \sigma_{o}$ is nominal stress, $\lambda=\left(l_{u} / l_{o}\right)$ is elongation ratio.

1) Sphere $(a=b=c, d=2 a)$ : for all location

$\sigma_{\theta}=\sigma_{z}=p a / 2 t^{\prime}, t^{\prime}$ is actual wall thickness

$\sigma_{r}=-p$, the initial wall thckness $t=1 \mathrm{~mm}$ (assumed)

thickness reduction $t^{\prime}=1 / n^{2}$, expansion ratio $n=d_{i} / d_{0}$

For example, as in Figure 1 and Figure 2, the stress of an early detected $3 \mathrm{~mm}$ spherical aneurysm is $0.75 \mathrm{p} / \mathrm{t}^{\prime}$.

2) Spheroid $(a, b=c)$ : at the top $T$
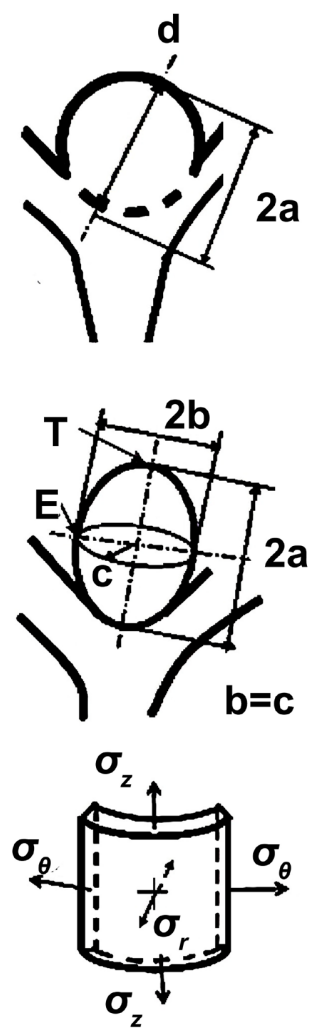

Figure 3. Coordinate representation of stresses acting on aneurysm wall: true stress can be calculated by using the actual thickness $(t)$ at the rupture. 


$$
\begin{aligned}
& \sigma_{\theta}=\sigma_{z}=p a^{2} / 2 b t^{\prime}, \text { which is }(a / b) \text { time of the sphere. } \\
& \sigma_{r}=-p, \quad t^{\prime}=1.06 / n^{2}
\end{aligned}
$$

The coefficient (1.06) was obtained in case that $a=1,2,3,4,5,6, b / a=0.4$, $0.5,0.6,0.8$, and $c / a=0.2,0.5$.

At the equator E: when $a / b=\sqrt{2}$, hoop stress $\sigma_{\theta}=0$.

$$
\begin{aligned}
\sigma_{\theta} & =p a / t^{\prime}\left[1-\frac{1}{2}\left(a^{2} / b^{2}\right)\right] \\
\sigma_{z} & =p a / 2 t^{\prime}: \text { the same as sphere } \\
\sigma_{r} & =-p, \quad t^{\prime}=1.06 / n^{2}
\end{aligned}
$$

For material failure problems under multi-axial load conditions, an equivalent uniaxial tensile stresses (such as the von Mises stress) are commonly used as a criterion for isotropic and ductile materials. Blood vessels, on the other hand, are viscoelastic materials, but the dilation of aneurysms is a very slow phenomenon (the function of time is approximately zero and the viscosity term is small). Therefore, we used the von Mises stress fracture criteria as in a textbook of solid mechanics.

The von Mises stress is expressed by

$$
\sigma_{\text {Mises }}=\left\{\left[\left(\sigma_{1}-\sigma_{2}\right)^{2}+\left(\sigma_{2}-\sigma_{3}\right)^{2}+\left(\sigma_{1}-\sigma_{3}\right)^{2}\right] / 2\right\}^{1 / 2}
$$

And the rupture criterion is $\left(\sigma_{\text {Misses }}\right) \geq\left(\sigma_{u}\right.$, arterial tensile strength $)$

where $\sigma_{1}, \sigma_{2}$, and $\sigma_{3}$ are three principal stresses: $\sigma_{1}=\sigma_{\theta}, \sigma_{2}=\sigma_{z}$ and $\sigma_{3}=\sigma_{r}$ at the crown top and at the equator. That is, if the von Mises stress is equal to or greater than the patient's arterial strength (true tensile stress), the arterial wall cracks and the aneurysm will rupture.

As an example for a spherical aneurysm with the initial diameter $d_{1}=3 \mathrm{~mm}, t_{1}$ $=1 \mathrm{~mm}$, and dilated diameter $d^{\prime}=9 \mathrm{~mm}, t^{\prime}=(1 / 3)^{2}$, using Equation (1) the stresses are

$$
\sigma_{1}=\sigma_{2}=\sigma_{\theta}=\sigma_{z}=20.25 p=323.2 \mathrm{kPa},
$$

and $\sigma_{3}=\sigma_{r}=-p=-16 \mathrm{kPa}$ (when $p=120 \mathrm{mmHg}$ ).

From Equation (4), $\sigma_{\text {Misses }}=339.2 \mathrm{kPa}$, which is smaller than arterial strengths $0.5-2.1 \mathrm{MPa}$ (these data were measured using the common carotid artery of 9 -autopsy of 80 's by authors), therefore this aneurysm will not rupture. However, since strength varies from person to person, it is necessary to measure the strength in vivo. As an example, author's methods for measuring strength using echo images and the natural vibration analysis [35] [36] are described in the Appendix.

\subsection{Hazard Ratio in the UCAS Study}

Figure 4 shows the relationship between the hazard ratio by the UCAS and the aneurysm size $\left(d_{i}\right)$, and also the relationship between the stress increase ratio, $\left(\sigma / \sigma_{3 \mathrm{~mm}}\right)$, of 3-mm-aneurysm and $d_{i}$. 


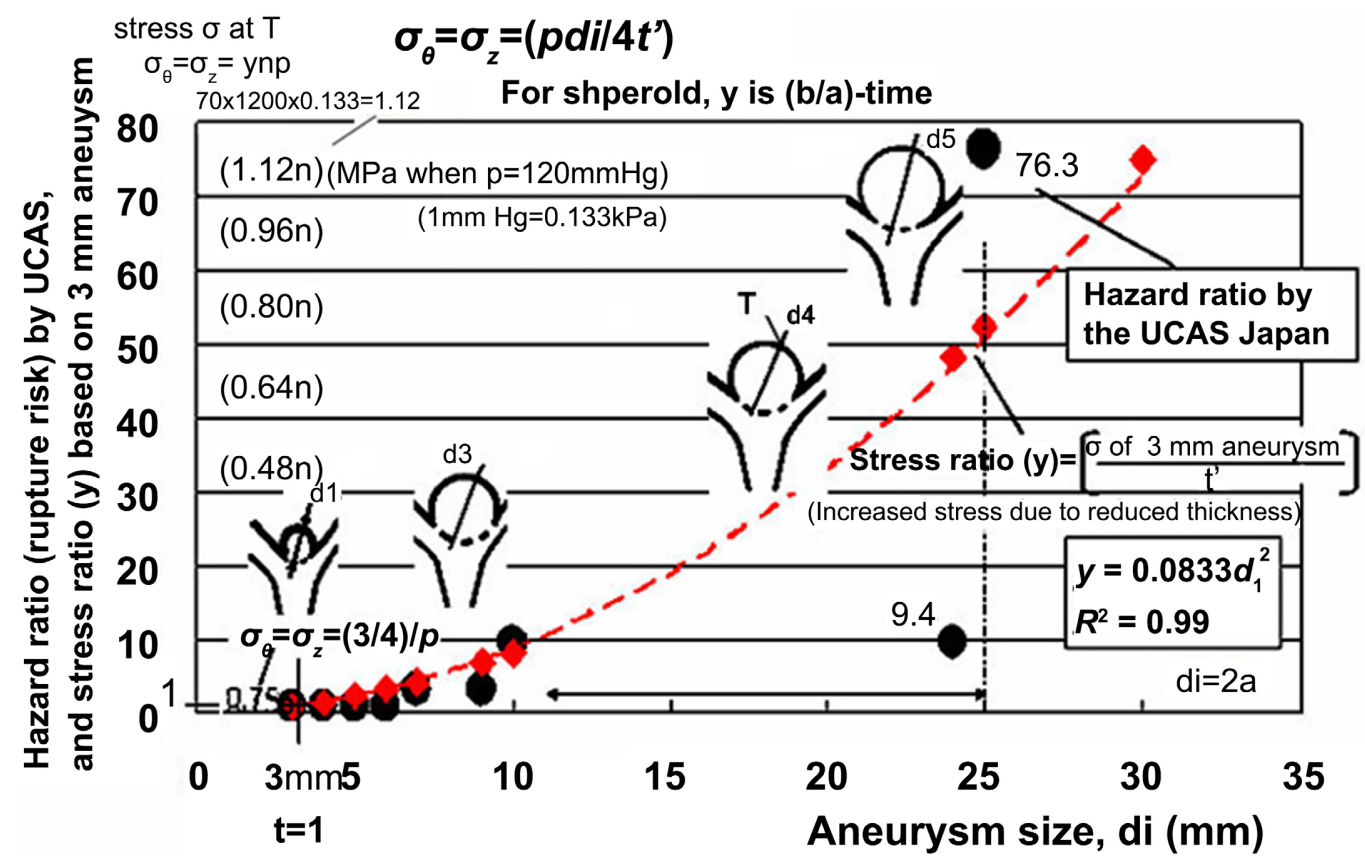

Figure 4. The relationship between the hazard ratio of UCAS and aneurysm size, and the relationship between the stress ratios $(y)$ based on 3-mm aneurysm and aneurysm size: $y$-value curve (red dashed line) is equivalent to the hazard ratio value, and the wall stress is $\sigma_{\theta}=n y p$.

The true stress of the wall with increasing $d_{i}$ is as follows using Equation (1).

$$
\sigma_{\theta}=\sigma_{z}=p a^{\prime} / 2 t^{\prime}=\left(a_{1} n^{2} / 2 t_{1}\right) n p=y n p
$$

where $a^{\prime}=a_{1} n, t^{\prime}=t_{1} / n^{2}$, and $y=a_{1} n^{2} / 2 t_{1}, 2 a_{i}=d_{i}$.

The $y$-curve (red dashed line) in Figure 4 represents the true stress of the dilated aneurysm, and the true stress is given by multiplying by $n p$. Therefore, this figure indicates that there is a good relationship between the hazard ratio of UCAS and the $y$-curve. The correlation equation for the $y$-curve is as follows:

$$
y=0.0833 d_{i}^{2}, R^{2}=0.99 .
$$

Therefore, the hazard ratio corresponds to the magnitude of true stress, which is very informative to assess rupture of aneurysm. For an example, when $d_{i}=2 a^{\prime}$ $=9 \mathrm{~mm}$, and $n=9 / 3=3$, the ratio $(y)$ is 6.74 , then $\sigma_{\theta}=y n p=20.24 p$, which is the same with $20.25 p$ of the result using Equation (1). Therefore, we can quickly obtain the true stress of the wall from the aneurysm size $\left(d_{i}\right)$ and Equation (8).

\section{Daughter sac}

Figure 5 shows the relation between true stresses $\left(\sigma_{\theta}\right.$ and $\left.\sigma_{z}\right)$ and size $\left(d_{i}\right)$ at the crown top (T) and at the equator (E) of sphere and spheroid models.

For the sphere, the stress $\sigma_{\theta}=\sigma_{z}$ is the same uniform stress state. It is shown by the dashed red line for comparison with other stresses.

For the spheroid, $\sigma_{\theta}=\sigma_{z}$ at the T, and $\sigma_{\theta}$ and $\sigma_{z}$ increase as the value of $(b / a)$ decreases, this is $(a / b)$ times that of the sphere.

At the E, $\sigma_{z}$ is the same value as the sphere. The $\sigma_{\theta}$ is zero when $b / a=1 / \sqrt{2}$, and it is greater than $b / a=1 / \sqrt{2}, \sigma_{\theta}$ becomes negative. Therefore, the spheroid 


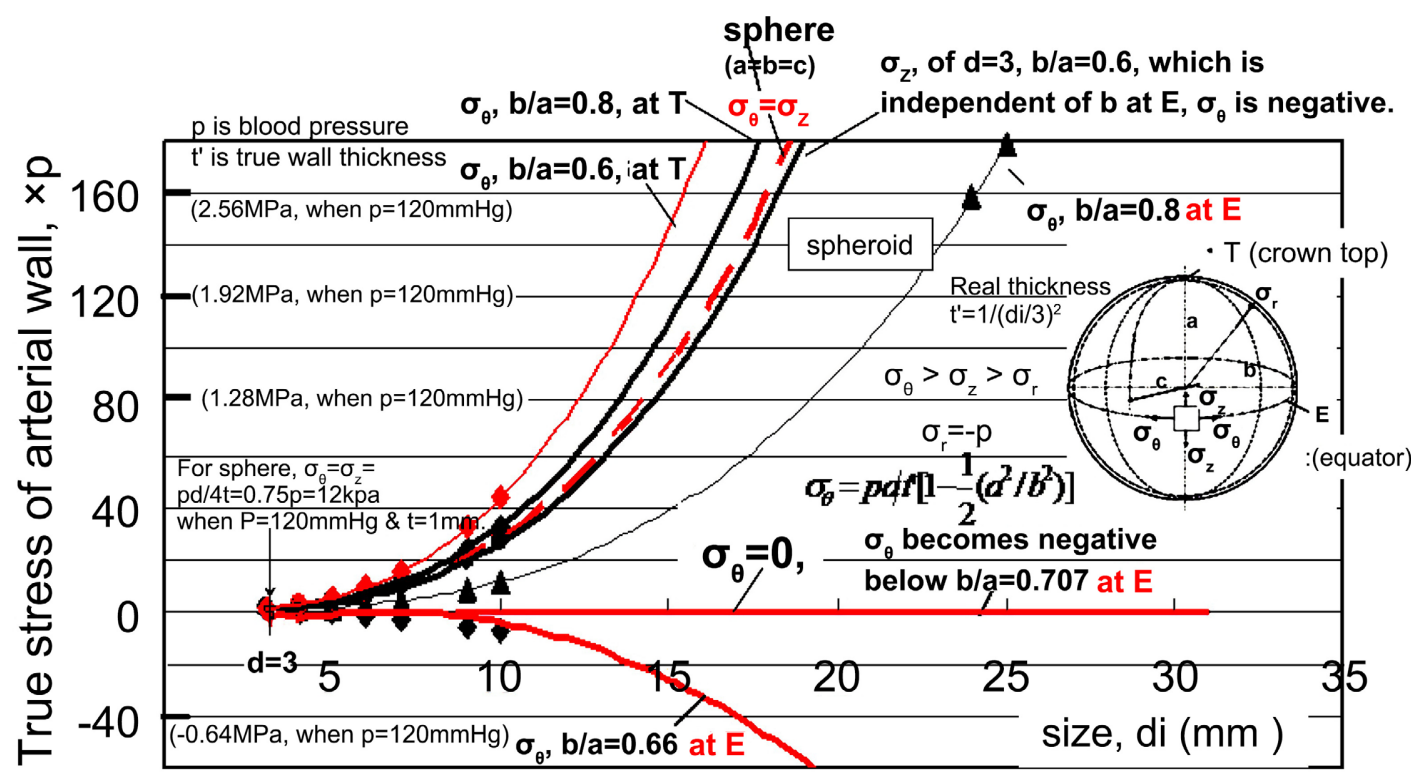

Figure 5. The relationship between true stress $\left(\sigma_{\theta}\right.$ and $\left.\sigma_{z}\right)$ of arterial wall and size $\left(d_{i}\right)$ at the crown top (T) and at the equator (E) of the sphere and spheroid models: when $b / a$ is less than 0.707 , negative hoop stress is applied to the equator, which can cause the sphere to become concave.

deforms inward on the equator and the deformation depends on the stiffness of the material.

In addition, since $\sigma_{\theta}$ and $\sigma_{z}$ at $\mathrm{T}$ are large, the deformation of the crown top area is promoted, and it may become a cocoon-like shape.

Figure 6(a) shows the hazard risk ratio for both types with and without of daughter sac, quoted from the UCAS study [19] [20]. In the figure, the hazard ratio was 1.64 , but no aneurysm size data was shown.

Figure $6(\mathrm{~b})$ shows the relationship between $(b / a)$ and the stress ratio (sphe$\mathrm{roid} / \mathrm{sphere}$ ) by using Equation (2). The stress ratio increases with the value of $z$ $=(a / b)$, and the ratio of 1.64 correspond to a spheroid of $(b / a)=0.61$. That is, the stress at $\mathrm{T}$ of spheroidal aneurysm is 1.64 times the stress of the sphere. Therefore, the above example $\left(d^{\prime}=9 \mathrm{~mm}, \sigma_{\text {Misses }}=339.2 \mathrm{kPa}\right)$ is $339.2 \times 1.64=$ $556.3 \mathrm{kPa}$, which increases the possibility of rupture. This is the difference between the two types, sphere and spheroid. As shown in the figures, these stresses related to size and shape are expected to be useful data for assessing rupture.

\subsection{Rupture Risk Assessment Based on Biomechanics}

As mentioned above, aneurysm ruptures when the true stress of the vessel wall due to blood pressure equals the strength of the patient's artery. Therefore, major tasks are location, shape, size, and wall stress, and blood vessel strength from a biomechanical point of view (Figure 7).

(a) Location and shape: types of aneurysms and size change

(b) True stress: wall stress due to reduced thickness

(c) In vivo strength: strength of each patient's artery by non-invasive measurement 


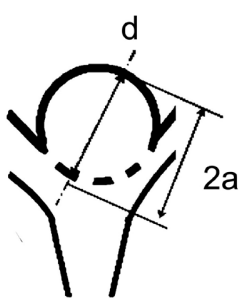

without daughter sac

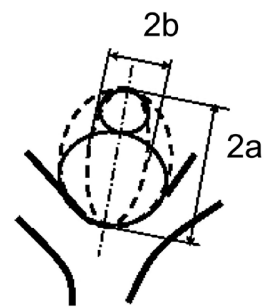

with daughter sac

\begin{tabular}{lcc}
\hline Hazard ratio: & 1 & 1.64 \\
\hline Annual rupture rate (\%) $:$ & 0.73 & 2.33 \\
\hline
\end{tabular}

(a)

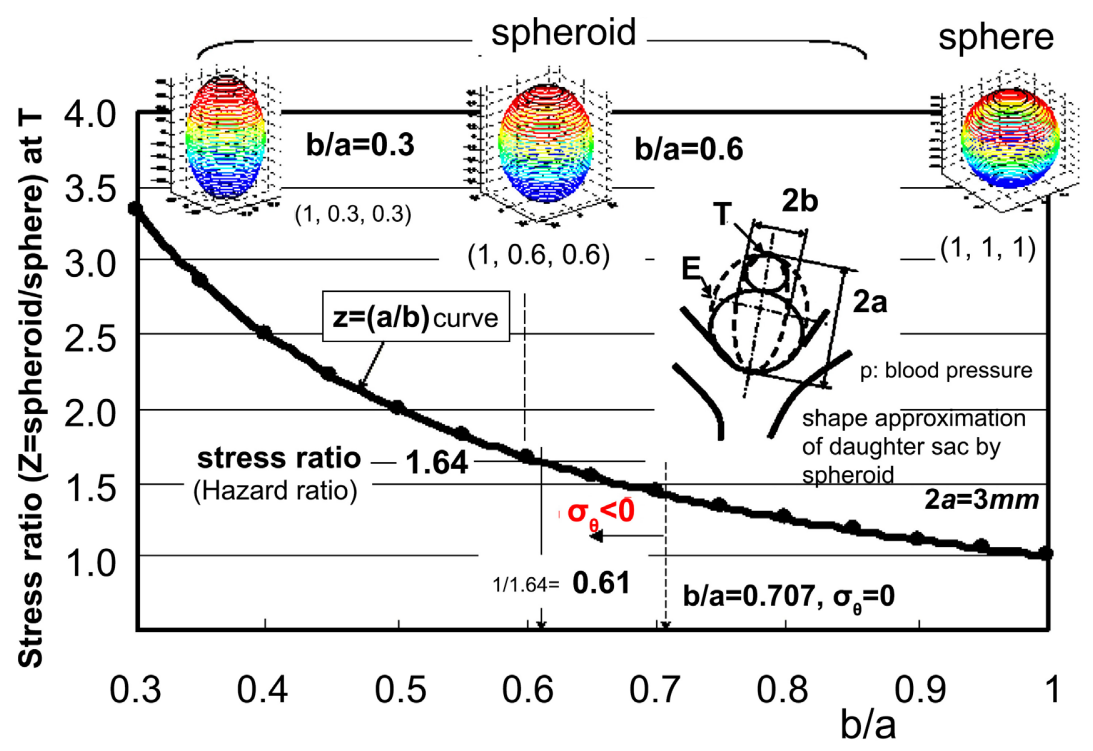

(b)

Figure 6. (a) The hazard ratio for both types with and without of daughter sac which derived by the UCAS Japan study [20]: the ratio suggests that the stress is 1.64 times larger than that of a spherical without daughter sac aneurysm. (b) Change in the stress ratio (spheroid/sphere) vs. (b/a): the ratio increases with $z=(a / b)$ value.

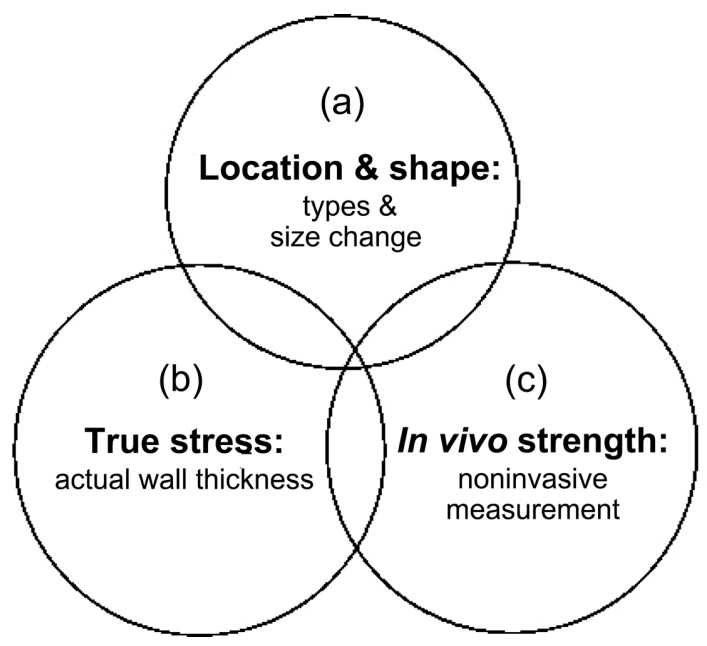

Figure 7. Major tasks required to assess the risk of aneurysm rupture from biomechanical viewpoint. 
In this consideration, we used a spherical model to examine the hazard risk of UCAS analyzed statistically. However, in actually, shape of the aneurysm is irregular and locally discontinuous and individual stress analysis of the aneurysm requires considerable time.

Then, once again, we give attention to Figure 5, the difference between the data of UCAS and the spherical model can be considered as the difference between clinical data and model geometry. For example, at $d_{i}=25 \mathrm{~mm}$, the hazard ratio $=76.3$ (black dot) and 52 on the y-curve (Equation (8), red dash line), and this difference is about 1.5 times (76.3/52). Therefore, this is one of differences between clinical data and the results of the spherical model. Therefore, if the actual shape of the aneurysm is irregular, the hazard risk can be predicted to be about 1.5 times. In the future, it will be necessary to consider quantitatively based on further clinical data.

This report mainly described the risk of rupture due to blood pressure and dilation of the aneurysm. Hemodynamics, on the other hand, are thought to play an important role in the pathogenesis and treatment of head aneurysms [34] [35], but it is difficult to measure the hemodynamics of interest in vivo. This study does not address the problem of impaired blood flow to the lining of blood vessels, hemodynamic analysis.

\section{Conclusions}

The biomechanical signification of the hazard risk ratio of 6697 unruptured aneurysms reported by the UCAS Japan research group based on statistical method was discussed using a spherical aneurysm model. It is summarized below.

1) As the unruptured aneurysm expands, the wall thickness decreases by a square of the aneurysm expansion ratio, therefore the true stress on the wall increases by the square. Especially the size is up to $10 \mathrm{~mm}$, the change is large, and so it is important to manage the aneurysm size.

2) It was found that the hazard risk ratio of UCAS corresponds to stress of the aneurysm wall, and multiplying this value by the patient's blood pressure gives the true stress value.

3) When size of aneurysm was about 10 to $25 \mathrm{~mm}$, the difference in hazard risk ratio between the spherical model and the clinical aneurysm was about 1.5 times (difference between actual and spherical shape). It is important to manage the true stress of the aneurysm wall and the strength of the patient's blood vessels to quantitatively determine the likelihood of rupture.

4) In case of shape of the aneurysm is close to a thin ellipsoid, it is highly possible that a daughter sac will be formed.

\section{Conflicts of Interest}

The authors declare no conflicts of interest regarding the publication of this paper.

\section{References}

[1] Department of Surgery, Graduate School of Biomedical \& Health Sciences, Hiro- 
shima University, Japan.

http://surgery1.hiroshima-u.ac.jp/about/diagnosis/Cardiovascular/whats-an-aneury sm-q-and-a/

[2] Johnston, K.W., Rutherford, R.B., Tilson, M.D., Shah, D.M., Hollier, L. and Stanley, J.C. (1991) Suggested Standards for Reporting on Arterial Aneurysms. Journal of Vascular Surgery, 13, 452-458. https://doi.org/10.1067/mva.1991.26737

[3] Chaikof, E.L., Brewster, D.C., Dalman, R.L., Makaroun, M.S., Illig, K.A., Sicard, G.A., Timaran, C.H., Upchurch, G.R. and Veith, F.J. (2009) The Care of Patients with an Abdominal Aortic Aneurysm: The Society for Vascular Surgery Practice Guidelines. Journal of Vascular Surgery, 50, S2-S49.

https://doi.org/10.1016/j.jvs.2009.07.002

[4] Patel, M.I., Hardman, D.T., Fisher, C.M. and Appleberg, M. (1995) Current Views on the Pathogenesis of Abdominal Aortic Aneurysms. Journal of the American College of Surgeons, 181, 371-382.

[5] Sakalihasan, N., Limet, R. and Defawe, O.D. (2005) Abdominal Aortic Aneurysm. The Lancet, 365, 1577-1589. https://doi.org/10.1016/S0140-6736(05)66459-8

[6] Tompson, B.G., Brown, R.D., Amin-Hanjani, S., Broderick, J.P., Cockroft, K.M., et al. (2015) Guidelines for the Management of Patients with Unruptured Intracranial Aneurysms: A Guideline for Healthcare Professionals from the American Heart Association/America Stroke Association. Stroke, 46, 2368-2400. https://doi.org/10.1161/STR.0000000000000070

[7] Juvela, S., Porras, M. and Heiskanen, O. (1993) Natural History of Unruptured Aneurysms: A Long-Term Follow-Up Study. Journal of Neurosurgery, 79, 174-182. https://doi.org/10.3171/jns.1993.79.2.0174

[8] The International Study of Unruputured Intracranial Aneurysms Investigators (1998) Unruptured Intracranial Aneurysms-Risk of Rupture and Risks of Surgical Intervention. The New England Journal of Medicine, 339, 1725-1733. https://doi.org/10.1056/NEJM199812103392401

[9] Jellinger, K. (1977) Pathology of Intracerebral Hemorrhage. Zentralbl Neurochir, 38, 29-42.

[10] Jakubowski, J. and Kendall, B. (1978) Coincidental Aneurysms with Tumors of Pituitary Origin. Journal of Neurology, Neurosurgery and Psychiatry, 41, 972-979. https://doi.org/10.1136/jnnp.41.11.972

[11] Sweeting, M.J., Thompson, S.G., Brown, L.C. and Powell, J.T. (2012) Meta-Analysis of Individual Patient Data to Examine Factors Affecting Growth and Rupture of Small Abdominal Aortic Aneurysms. British Journal of Surgery, 99, 655-665. https://doi.org/10.1002/bjs.8707

[12] Rughani, G., Robertson, L. and Clarke, M. (2012) Tatment for Small Abdominal Aortic Aneurysms. Cochrane Database of Systematic Reviews, 9, CD009536. https://doi.org/10.1002/14651858.CD009536

[13] Ernst, C.B. (1993) Abdominal Aortic Aneurysm. The New England Journal of Medicine, 328, 1167-1172. https://doi.org/10.1056/NEJM199304223281607

[14] Cosford, P.A. and Leng, G.C.(2007) Screening for Abdominal Aortic Aneurysm. Cochrane Database of Systematic Reviews, 2, CD002945.

https://doi.org/10.1002/14651858.CD002945.pub2

[15] Larsson, E., Granath, F., Swedenborg, J. and Hultgren, R. (2009) A Population-Based Case-Control Study of the Familial Risk of Abdominal Aortic Aneurysm. Journal of Vascular Surgery, 49, 47-51. 
https://doi.org/10.1016/j.jvs.2008.08.012

[16] Brown, P.M., Zelt, D.T. and Sobolev, B.G. (2003) The Risk of Rupture in Untreated Aneurysms: The Impact of Size, Gender, and Expansion Rate. Journal of Vascular Surgery, 37, 280-284. https://doi.org/10.1067/mva.2003.119

[17] Steiner, T., Juvela, A.S., Unterberg, D.A., Jung, B.C., Forsting, M. and Rinkel, G. (2013) European Stroke Organization Guidelines for the Management of Intracranial Aneurysms and Subarachnoid Haemorrhage. Cerebrovascular Diseases, 35, 93-112. https://doi.org/10.1159/000346087

[18] Erbel, R., Aboyans, V., Boileau, C., et al. (2014) 2014 ESC Guidelines on the Diagnosis and Treatment of Aortic Diseases. European Heart Journal, 35, 2873-2926. https://academic.oup.com/eurheartj/article/35/41/2873/407693

[19] The UCAS Japan Investigators, Morita, A., Kirino, T., Aoki, N., Gukughara, S., Hasimoto, N., Nakayama, T., Sakai, M., Teramoto, A., Tominari, S. and Yosinmoto, T. (2012) The Natural Course of Unruptured Cerebral Aneurysms in a Japanese Cohort. The New England Journal of Medicine, 366, 2474-2482. https://doi.org/10.1056/NEJMoa1113260

[20] Guidelines for Diagnosis and Treatment of Aortic Aneurysm and Aortic Dissection (2011) The Digest Version by JCS Joint Working Group by Japanese Circulation Society and Other Six Societies. http://jns.umin.ac.jp/member/UCAS/ucas.html

[21] Murayama, Y., Takao, H., Ishibashi, T., Saguchi, T., Ebara, M., Yuki, I., Arakawa, H., Irie, K., Urashim, M. and Molyneux, A.J. (2016) Risk Analysis of Unruptured Intracranial Aneurysms Prospective 10-Year Cohort Study. Stroke, 47, 365-371. https://doi.org/10.1161/STROKEAHA.115.010698

[22] Jim, J. and Thompson, R.W. (2021) Clinical Features and Diagnosis of Abdominal Aortic Aneurysm.

https://www.uptodate.com/contents/clinical-features-and-diagnosis-of-abdominalaortic-aneurysm\#H1382371318

[23] Guirguis-Blake, J.M., Beil, T.L., Sun, X., Senger, C.A. and Whitlock, E.P. (2014) Primary Care Screening for Abdominal Aortic Aneurysm: A Systematic Evidence Review for the U.S. Preventive Services Task Force [Internet]. Agency for Healthcare Research and Quality (US), Rockville.

[24] Maier, A., Gee, M.W., Reeps, C., Pongratz, J., Eckstein, H.H. and Wall, W.A. (2010) A Comparison of Diameter, Wall Stress, and Rupture Potential Index for Abdominal Aortic Aneurysm Rupture Risk Prediction. Annals of Biomedical Engineering, 38, 3124-3134. https://doi.org/10.1007/s10439-010-0067-6

[25] Fillinger, M.F., Raghavan, M.L., Marra, S.P., Cronenwett, J.L. and Kennedy, F.E. (2002) In Vivo Analysis of Mechanical Wall Stress and Abdominal Aortic Aneurysm Rupture Risk. Journal of Vascular Surgery, 36, 589-597.

https://doi.org/10.1067/mva.2002.125478

[26] Vorp, D.A. and Vande Geest, J.P. (2005) Biomechanical Determinants of Abdominal Aortic Aneurysm Rupture. Arteriosclerosis, Thrombosis, and Vascular Biology, 25, 1558-1566. https://doi.org/10.1161/01.ATV.0000174129.77391.55 https://www.ahajournals.org/doi/full/10.1161/01.ATV.0000174129.77391.55

[27] Vande Geest, J.P., Di Martino, E.S., Bohra, A., Makaroun, M.S. and Vorp, D.A. (2006) A Biomechanics-Based Rupture Potential Index for Abdominal Aortic Aneurysm Risk Assessment. Annals of the New York Academy of Sciences, 1085, 11-21. https://doi.org/10.1196/annals.1383.046

[28] Doyle, B.J., Callanan, A., Walsh, M.T., Grace, P.A. and McGloughlin, T.M. (2009) A Finite Element Analysis Rupture Index (FEARI) as an Additional Tool for Abdo- 
minal Aortic Aneurysm Rupture Prediction. Vascular Disease Prevention, 6, 114-121.

[29] Erhart, P., Hyhlik-Dürr, A., Geisbüsch, P., Kotelis, D., Müller-Eschner, M., Gasser, T.C., von Tengg-Kobligk, H. and Böckler, D. (2015) Finite Element Analysis in Asymptomatic, Symptomatic, and Ruptured Abdominal Aortic Aneurysms: In Search of New Rupture Risk Predictors. European Journal of Vascular and Endovascular Surgery, 49,239-245. https://doi.org/10.1016/j.ejvs.2014.11.010

[30] Watton, P., Hill, N. and Heil, M.A. (2004) A Mathematical Model for the Growth of the Abdominal Aortic Aneurysm. Biomechanics and Modeling in Mechanobiology, 3, 98-113. https://doi.org/10.1007/s10237-004-0052-9

[31] Volokh, K.Y. and Vorp, D.A. (2008) A Model of Growth and Rupture of Abdominal Aortic Aneurysm. Journal of Biomechanics, 41, 1015-1021.

https://doi.org/10.1016/j.jbiomech.2007.12.014

[32] Gasser, T.C. (2016) Biomechanical Rupture Risk Assessment: A Consistent and Objective Decision-Making Tool for Abdominal Aortic Aneurysm Patients. AORTA, 4, 42-60. https://doi.org/10.12945/j.aorta.2015.15.030

[33] Du, Y.K. and Lu, C.F. (2017) Modeling on Monitoring the Growth and Rupture Assessment of Saccular Aneurysms. Theoretical \& Applied Mechanics Letters, 7, 117-120.

[34] Sugiyama, S., Meng, H., Funamoto, K., Inoue, T., Fujimura, M., Nakayama, T., Omodaka, S., Shimizu, H., Takahashi, A. and Tominaga, T. (2012) Hemodynamic Analysis of Growing Intracranial Aneurysms Arising from a Posterior Inferior Cerebellar Artery. World Neurosurgery, 78, 462-468.

https://doi.org/10.1016/j.wneu.2011.09.023

[35] Metcalfe, R.W. (2003) The Promise of Computational Fluid Dynamics as a Tool for Delineating Therapeutic Options in the Treatment of Aneurysms. American Journal of Neuroradiology, 24,553-554.

[36] Nogata, F., Yokota, Y., Kawamura, Y., Mouri, T., Walsh, W.R., Kawamura, T. and Hotta, N. (2019) Towards the Application of AI Technology to Assess Risk of Aneurysm Rupture Based on Medical Imaging: Relations of Geometry, Size, Blood Pressure, and Wall Strength. International Journal of Computer and Information Technology, 8, 120-130.

https://www.researchgate.net/profile/Fumio-Nogata/research

[37] Nogata, F., et al. (2009) A Technique for Estimating Sclerosis of Carotid Artery with Ultrasonic Echo. In: Dössel, O. and Schlegel, W.C., Eds., World Congress on Medical Physics and Biomedical Engineering, Springer, Berlin, 655-658.

http://www.springerlink.com/

https://doi.org/10.1007/978-3-642-03882-2_175

[38] Nogata, F., Yokota, Y., Kawamura, Y., Mouri, T., Walsh, W.R., Kawamura, T., Goto, H.N. and Kagecika, K. (2017) Stiffness Estimation from Arterial Wall Vibration and Its Application: A New Earphone for Examining Arteriosclerosis between Music and Next Music. International Journal of Computer and Information Technology, 6, 7-13. 


\section{Appendix}

1) A method using echo images of the CCA [36] [37]

Measurement principle: Blood vessels have the property that their elongation and strength with aging shows non-linearity (viscoelasticity), therefore, the stiffness was defined by the linear gradient $(\mathrm{Eth}=\Delta \sigma / \Delta \varepsilon)$ between changes in resting blood pressure $\left(p_{d}-p_{s}\right)$.

The diameter variation of $d_{i}$ and $d_{o}$ with time is measured from B-mode moving image of a couple of heartbeats. And we assumed that $d_{o}=d_{i}+$ wall thickness $(t=0.5-0.6)$ from $t=0.4-0.8 \mathrm{~mm}$ of the age of $40 \mathrm{~s}-80 \mathrm{~s}$ in an anatomical textbook. The trial software developed for analyzing the variation of $d_{i}$ allows real-time measurement. The stiffness is

$$
\begin{gathered}
\text { Eth }=\sigma_{\theta i} / \varepsilon_{\theta i} \\
\sigma_{\theta i}=\left\{\left(\underline{d}_{o}^{2}+\underline{d}_{i}^{2}\right) p_{s}-\left(d_{o}^{2}+d_{i}^{2}\right) p_{d}\right\} /\left(d_{o}^{2}-d_{i}^{2}\right) \\
\varepsilon_{\theta i}=\Delta d_{i} / d_{i}
\end{gathered}
$$

From the continuity condition (incompressibility, no volume-change between $p_{s}$ and $\left.p_{d}\right)$, it is given as, $d_{o}^{2}-d_{i}^{2}=\underline{d}_{o}^{2}-\underline{d}_{i}^{2}$, where $\sigma_{\theta i}$ and $\varepsilon_{\theta i}$ are circumferential stress and strain at the inner wall (crack occurs on the inner surface), and underline means dilated diameter. The values of $d_{i}$ and $\underline{d}_{i}^{\prime}$ can be measured using ultrasonic B-mode video.

Next, an empirical correlation between Eth and fracture strength $\left(\sigma_{u}\right)$ was obtained from the tensile and internal pressure burst test data: common carotid artery (CCA) of $80 \mathrm{~s}$ and animals (young sheep), step-by-step loading and finally burst testing.

Figure A1 shows a correlation curve between the stiffness Eth and burst pressure $(\mathrm{Bp})$ as well as fracture strength $\left(\sigma_{u}\right)$. A correlation curve obtained (Figure A1) is,

$$
\begin{aligned}
\mathrm{Bp}= & \text { 7.0 Eth }{ }^{6}-109.7 \mathrm{Eth}^{5}+689.2 \mathrm{Eth}^{4}-2234.5 \mathrm{Eth}^{3}+3951.8 \mathrm{Eth}^{2} \\
& -3727.9 \mathrm{Eth}+1975.4, \operatorname{mmHg}(=133.3 \mathrm{~Pa})
\end{aligned}
$$

This Bp can calculate the predicted burst pressure of CCA from the Eth value using the echo images. Here, the size of CCA was calculated with the average values of test pieces $d_{o}=8.2, d_{i}=6.8 \mathrm{~mm}$, that is, $\sigma_{u}$ depends on the different diameters of each individual.

Figure A2 shows a trial system for estimating sclerosis of in vivo artery using B-mode image. A linear-type ultrasound transducer $(7.5 \mathrm{MHz}, 540 \times 420$ pixel, $0.0713 \mathrm{~mm} / \mathrm{pixel}$ ) was used. The example was 16 years male, and the estimated in vivo stiffness $\mathrm{Eth}=0.154 \mathrm{MPa}$, and $\mathrm{Bp}=1487 \mathrm{mmHg}(198 \mathrm{~Pa})$ from Equation (a2).

Because sclerosis of the artery proceeds in localized areas, we also measured stiffness distribution by moving the ultrasound transducer linearly and intervals of 3 - $5 \mathrm{~mm}$ for nine positions were analyzed.

Figure A3 shows the results of in vivo Eth in a 64-year-old woman (here, 5 


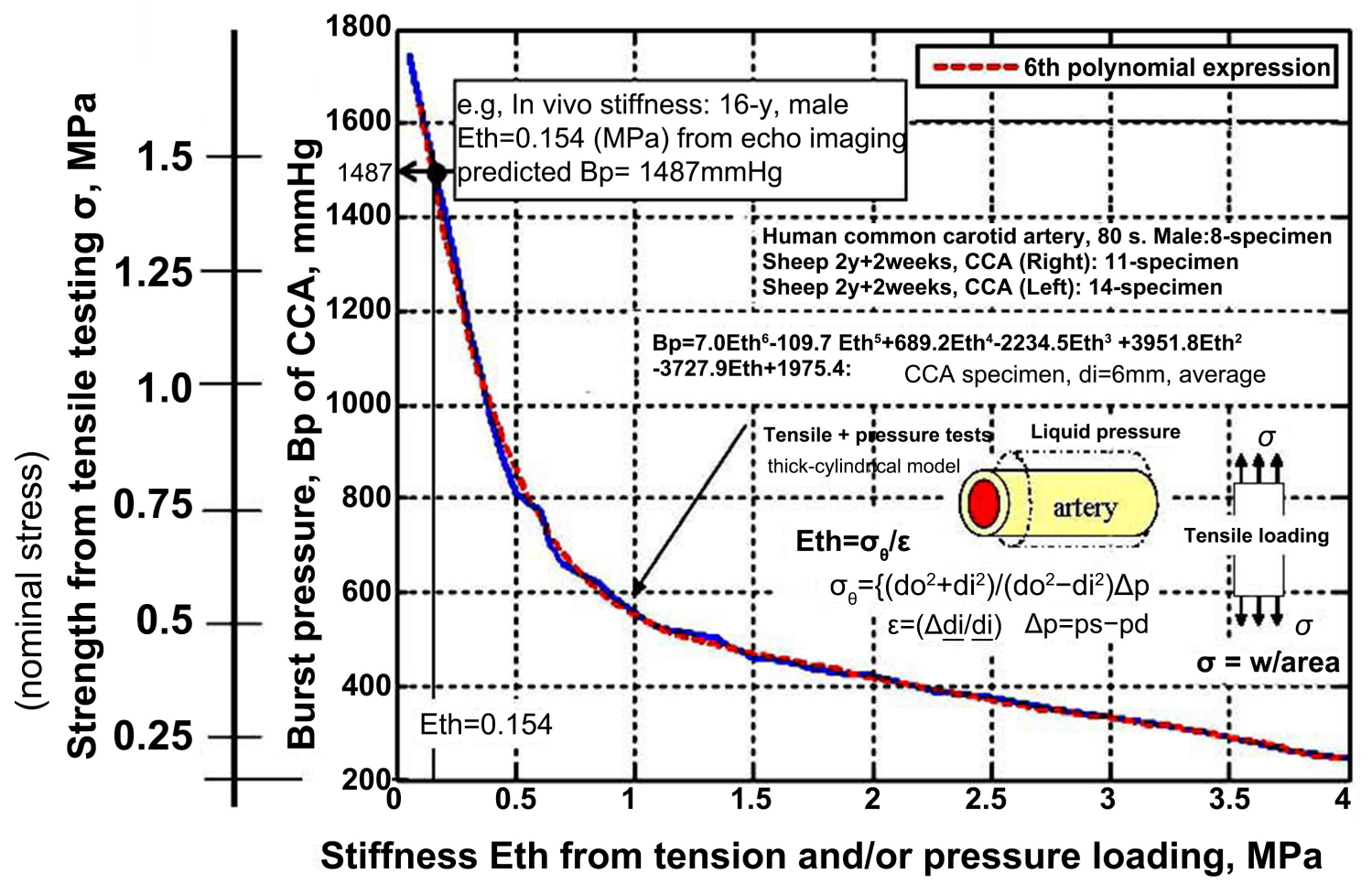

Figure A1. A correlation curve of measured data (CCA specimens of human and sheep, we measured at the UNSW, Australia).

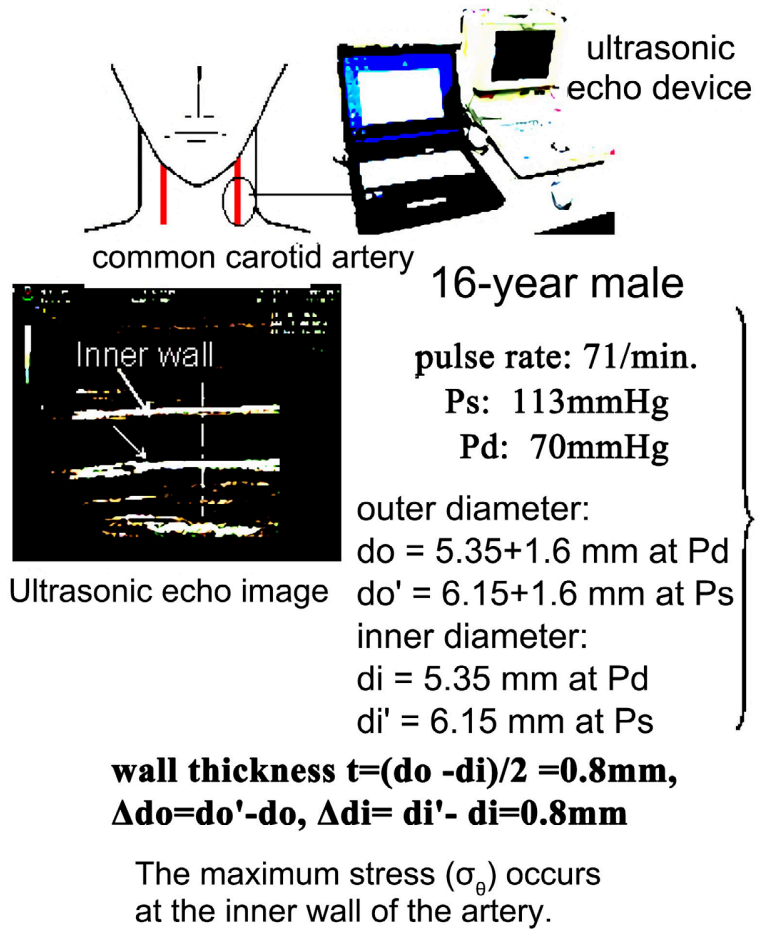

- a linear relationship is assumed between Ps and Pd, - stiffness (Young's modulus) Eth: $\left\{\begin{array}{l}\text { Eth }=\sigma_{\theta} / \varepsilon \\ \sigma_{\theta}=\left[\left(\mathrm{do}^{\prime 2}+\mathrm{di}^{\prime 2}\right) \mathrm{Ps}-\left(\mathrm{do}^{\prime 2}-\mathrm{di}^{2}\right) \mathrm{pd}\right] /\left(\mathrm{do}^{2}+\mathrm{di}^{2}\right) \\ \varepsilon=(\Delta \underline{\mathrm{di}} / \underline{\mathrm{di}}), \quad \Delta \mathrm{p}=\mathrm{ps}-\mathrm{pd}\end{array}\right.$

Estimated in vivo Eth $=0.154 \mathrm{MPa}$

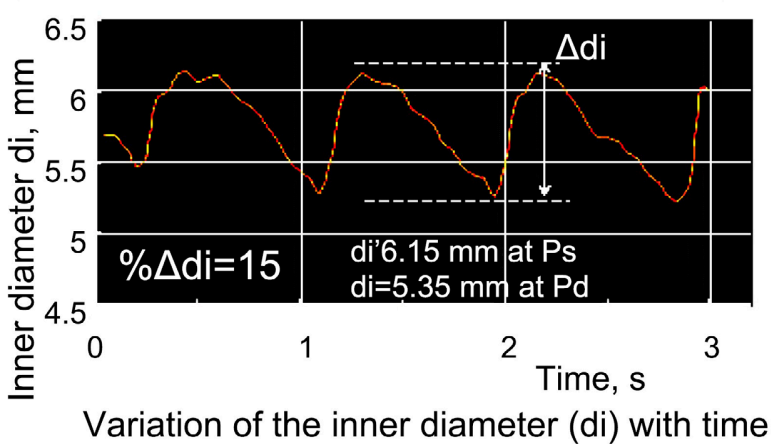

Figure A2. A trial system for estimating sclerosis of in vivo artery using B-mode image, and the result of young student data. 


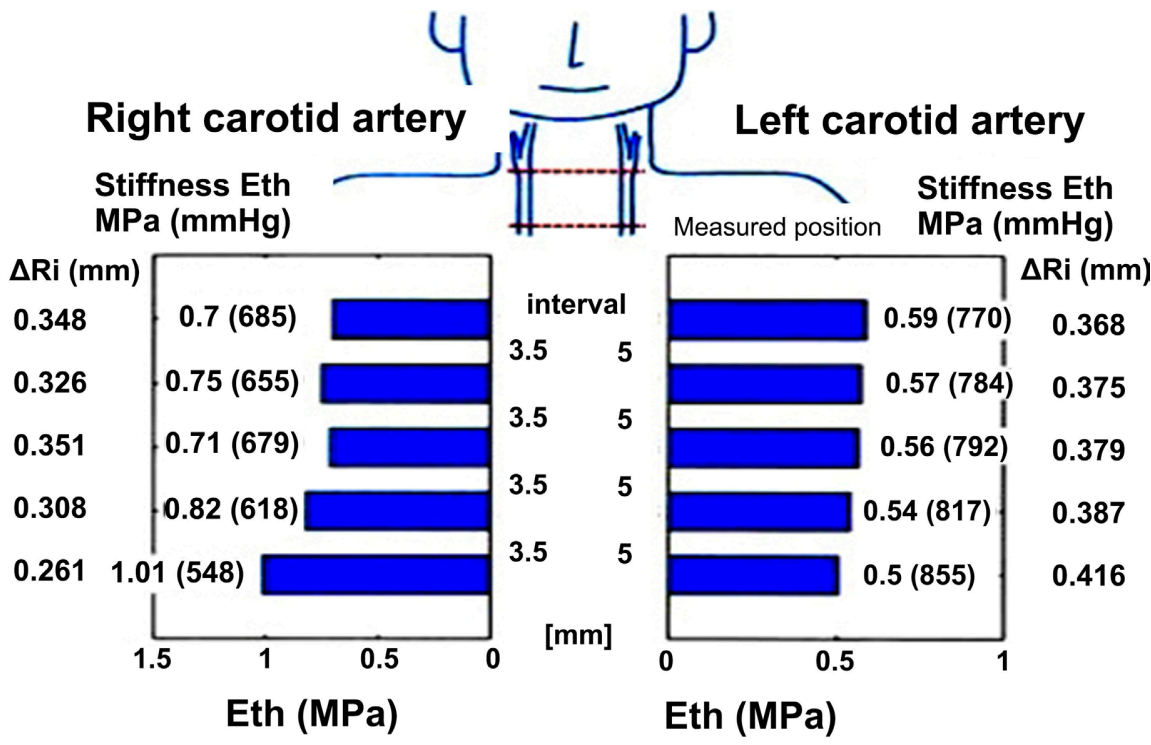

( $\Delta R \mathrm{i}$ is dilation of artery)

Figure A3. An example of stiffness (Eth) distribution showing the progression of the CCA sclerosis, measurements at 3 - $5 \mathrm{~mm}$ intervals (64-year-old woman), which took a total of several minutes.

pressure of the CCA from Equation (a2) is $\mathrm{Bp}=548 \mathrm{mmHg}(73.1 \mathrm{kPa})$. We believe that it is effective to use as an index of arteriosclerosis.

2) A method using the natural frequency of near artery [38]

Measurement principle: This is a new technique to measure stiffness (Eth) without the use of ultrasound equipment. The measurement principle is to use the relationship between the natural frequency of the blood vessel wall due to the heartbeat pulse wave and the stiffness. All structure has a natural frequency which is depend on mass $(m)$ and stiffness ( $k$, spring constant) of the system as response after applied force. Therefore, it can measure the natural frequency of bulge vibration generated.

A simple mass-spring system was used as in Figure A4, the equation of motion is $m\left(\frac{\mathrm{d}^{2} x}{\mathrm{~d} t^{2}}\right)+k x=0, \omega_{o}^{2}=k / m$, that is, the frequency is $f=\omega_{o} / 2 \pi$.

A prototype measurement device was made to analyze the vibration of the arterial wall. After confirming the performance of the measuring instrument using several tuning forks, the correlation equation between Eth (CCA, superficial temporal artery near the wall of the external auditory canal, brachial artery, and radial artery) and the natural frequency (fn) was obtained (Figure A5 and Equation (a3)).

$$
\text { Eth }=0.014(\mathrm{fn})-0.13, R^{2}=0.66 .
$$

Figure A6 shows a typical measurement example. Vibration waveforms were recorded at 5 points including the heart at the same time, and the natural frequency was obtained by FFT analysis. The heart waveform was used as the basic time axis. 


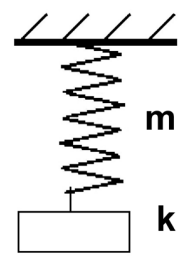

Figure A4. Mass and spring model.

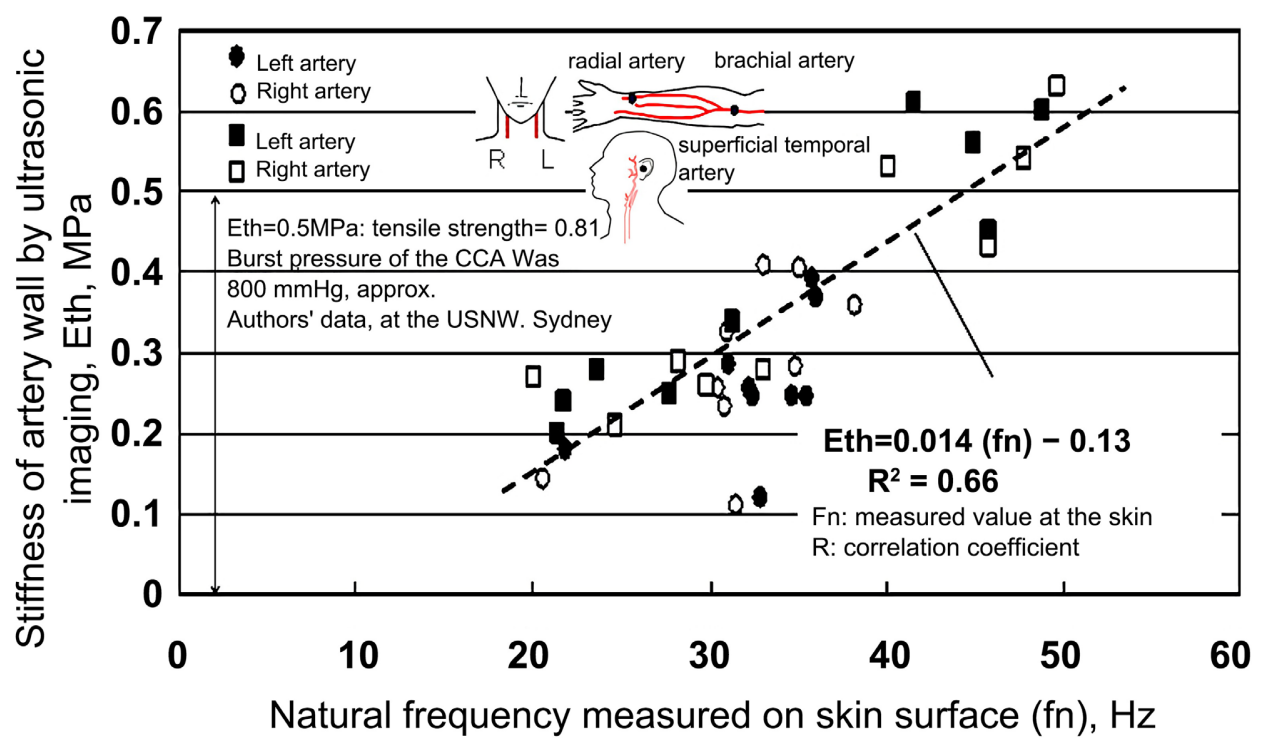

Figure A5. A correlation between the natural frequencies measured (fn) on the skin surface and stiffness (Eth) of the CCA using echo images.

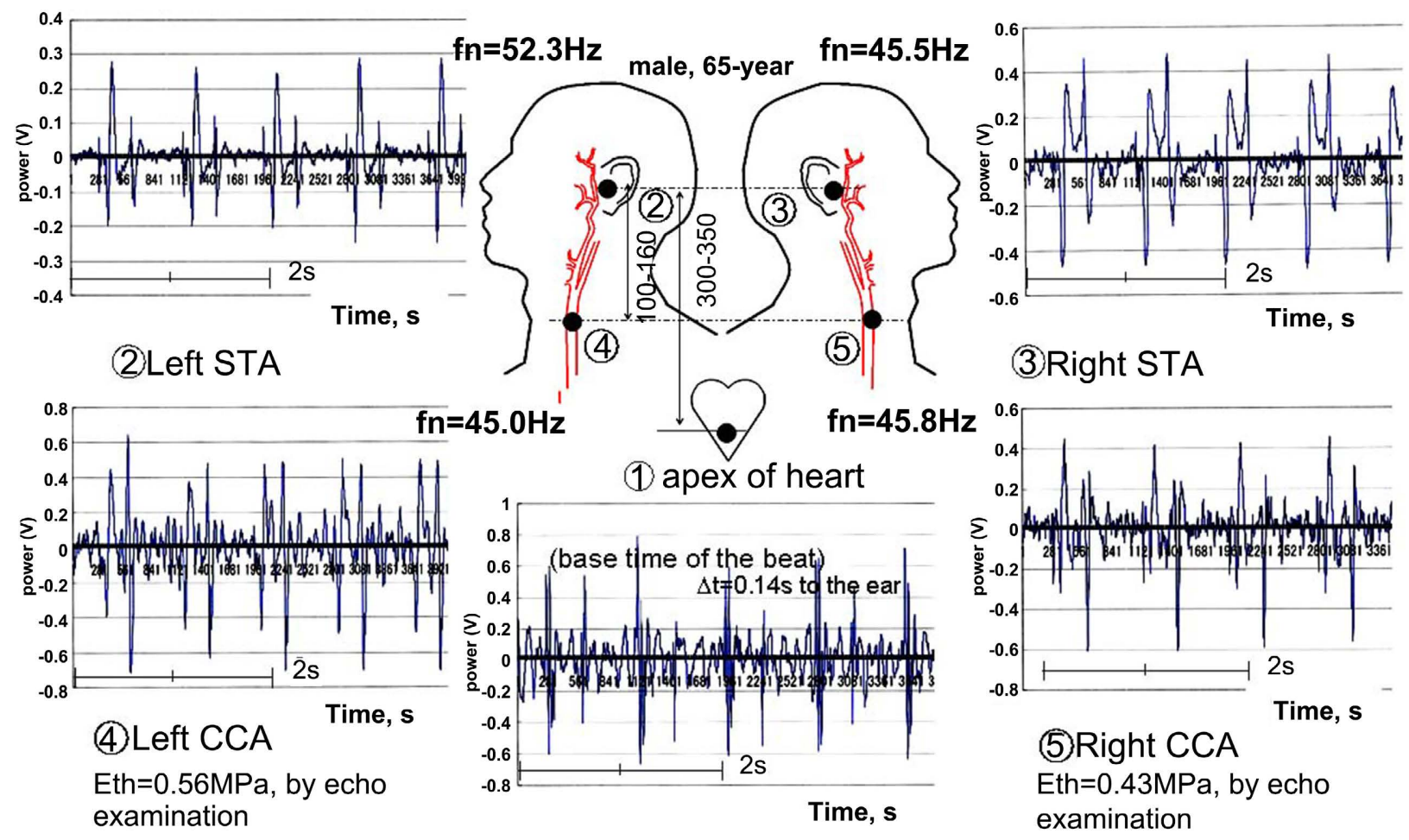

Figure A6. An example of free vibration of the arterial wall recorded simultaneously at five locations, age 65. 
Figure A7 shows the vision of a new earphone for testing for arteriosclerosis. This can be achieved by inserting a pair of sensors into both ear canals and measuring for a few seconds in a relaxed state. The plan is promising as a new earphone that can be measured while listening to music, is easy to use, is inexpensive, and has data recording and telemedicine via smart phone. Long-term recording is possible from young adulthood and lifelong vascular health can be managed.

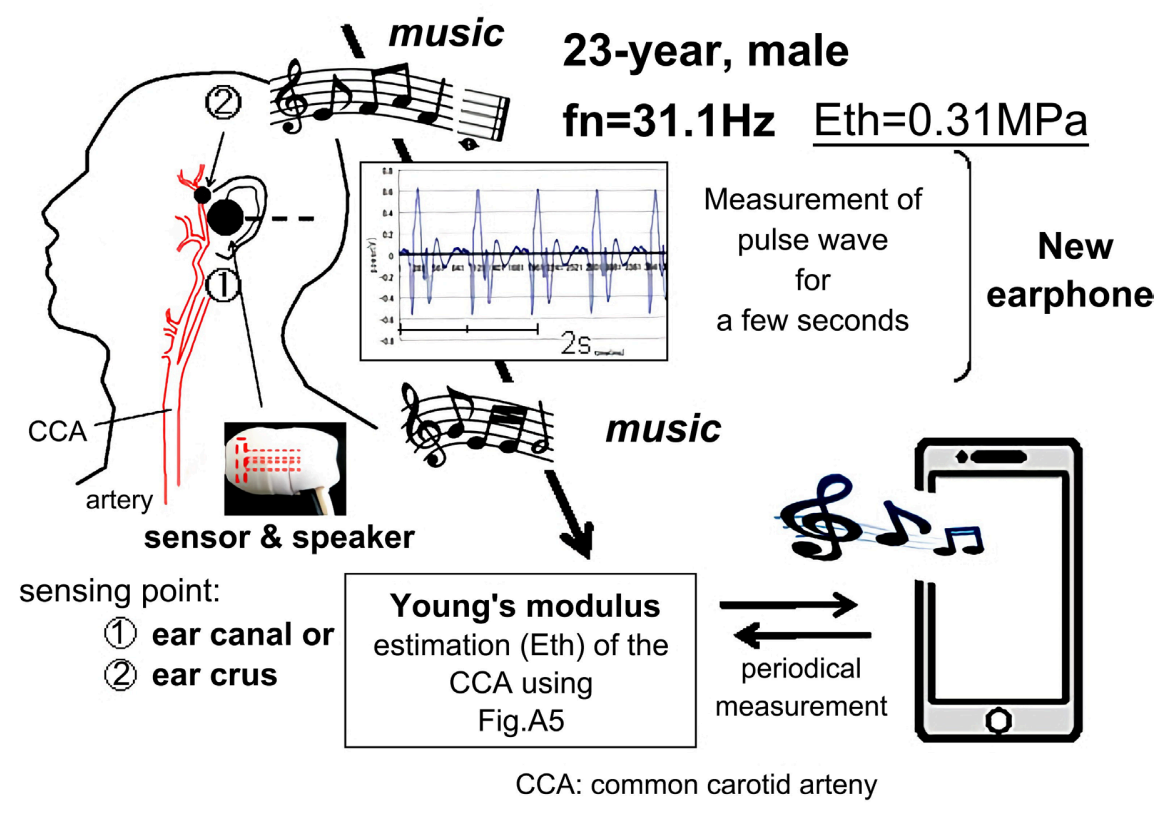

Figure A7. Vision of a new earphone for examining arteriosclerosis between music and next music, which allows that long-term recording is possible from young adulthood and lifelong vascular health can be managed. 